\title{
Numerical Simulation of Soil Displacement and Settlement in Deep Foundation Pit Excavations Near Water
}

\author{
Zhongjing Hu $\mathbb{D}^{1},{ }^{1}$ Qingbiao Wang ${ }^{\mathbb{D}},{ }^{2,3,4,5}$ Shuo Yang, ${ }^{6}$ Zhenyue Shi $\mathbb{D}^{1}{ }^{1}$ Bo Liu, ${ }^{7}$ \\ Hongxu Song, ${ }^{8}$ and Fuqiang Wang ${ }^{6}$ \\ ${ }^{1}$ College of Safety and Environmental Engineering (College of Safety and Emergency Management), Shandong University of Science \\ and Technology, Qingdao 266590, China \\ ${ }^{2}$ College of Resources, Shandong University of Science and Technology, Tai'an 271019, China \\ ${ }^{3}$ Shandong Provincial Key Laboratory of Civil Engineering Disaster Prevention and Mitigation, Shandong University of Science \\ and Technology, Qingdao 266590, China \\ ${ }^{4}$ State Key Laboratory of Mining Disaster Prevention and Control Co-Founded by Shandong Provence and the Ministry of Science \\ and Technology, Shandong University of Science and Technology, Qingdao 266590, China \\ ${ }^{5}$ National Engineering Laboratory for Coalmine Backfilling Mining, Shandong University of Science and Technology, \\ Tai'an 271019, China \\ ${ }^{6}$ College of Civil Engineering and Architecture, Shandong University of Science and Technology, Qingdao 266590, China \\ ${ }^{7}$ Shandong Zhengyuan Geological Resources Exploration Co. Ltd, Jinan 250101, China \\ ${ }^{8}$ College of Energy and Mining Engineering, Shandong University of Science and Technology, Qingdao 266590, China
}

Correspondence should be addressed to Qingbiao Wang; finddrem@163.com

Received 29 January 2021; Revised 2 March 2021; Accepted 10 March 2021; Published 8 October 2021

Academic Editor: Qiqing Wang

Copyright (c) 2021 Zhongjing Hu et al. This is an open access article distributed under the Creative Commons Attribution License, which permits unrestricted use, distribution, and reproduction in any medium, provided the original work is properly cited.

\begin{abstract}
Advancing urbanization in China requires large-scale high-rise construction and underground transportation projects. Consequently, there is an increasing number of deep foundation pits adjacent to water bodies, and accidents occur frequently. This study uses a numerical simulation method to study the stability of the deep foundation pit near water based on the Biot three-dimensional seepage-stress coupling model, with the open-cut section on the south bank of the Jinan Yellow River Tunnel Project as the engineering field test. This indicates the following: (1) the maximum horizontal displacement of the diaphragm wall occurred in the fifth excavation stage, and a horizontal brace effectively controlled the inward horizontal displacement of the foundation pit; (2) considering the effect of seepage in the soft soil foundation, the maximum vertical displacement of the ground surface at each excavation stage occurred adjacent to the underground continuous wall. As the depth of the foundation pit increased, the vertical surface settlement decreases gradually in the direction away from the excavation face; (3) considering the seepage conditions, within each interval of excavation of the foundation pit, the horizontal displacement of the continuous underground wall and ground settlement declined; and (4) the numerical simulation and field monitoring data were in good agreement. Under the conditions of accurate model simplification and parameter selection, numerical simulations can adequately forecast conditions of the actual project.
\end{abstract}

\section{Introduction}

With increasing urbanization in China, high-rise buildings and underground transportation projects have entered a period of large-scale construction. Particularly, deep and large foundation pit projects are becoming increasingly common in urban construction. Gong et al. [1-4] According to a notice issued by the Ministry of Housing and UrbanRural Development of China on the production safety accidents of housing and municipal engineering, there were 773 production safety accidents in housing and municipal engineering and 904 deaths in China in 2019. Further, 69 
were foundation pit collapses, accounting for $8.93 \%$ of the total, and $70-90 \%$ were caused by ineffective groundwater control. Therefore, in the construction of foundation pits, especially in water-rich areas, it is extremely important to adopt appropriate plans to control groundwater.

During excavation, the soil behind the wall (pile) moves into the pit, causing ground settlement around the foundation pit. When the settlement exceeds the critical value, foundation pit collapse occurs. Huang et al. [5-7] extensively researched the characteristics of the settlement of surrounding buildings caused by adjacent excavation of foundation pits. Wang and Wang [8] taking the Jinan Metro Line 1 deep foundation pit project as their research object analyzed on-site monitoring data during the excavation process and concluded that the maximum horizontal displacement occurred at one-third the pile height. Further, the maximum axial force and settlement value occurred at the second crossbrace position and the two corners away from the foundation pit, respectively. Huang et al. [5] proposed a new analytical solution for ground settlement caused by the excavation of deep foundation pits based on the elastic half-space Merlin solution. The change law of the earth pressure of normally consolidated soil after foundation pit excavation was analyzed, and the loading and unloading modulus formula was obtained by the parameter calculation method in the Ken-tension curve model. Zhang et al. [9] studied the field monitoring data of a deep foundation pit in soft soil, and the displacement and force characteristics of the diaphragm wall support during the excavation of the foundation pit were analyzed. It was also found that Hsieh and $\mathrm{Ou}$ can better describe the development trend of surface settlement. Niu et al. [10] focused on the deep and loose soil in central and southern China, and a model of lateral displacement and land subsidence of supporting structures was established with reference to Japanese standards. The research results show that the joint support scheme can effectively control the deformation of the foundation pit and its surroundings during excavation, and a reasonable supporting structure force can be determined.

The change in groundwater level is an important factor affecting the safety of the project foundation pit excavation and construction and a focus of scholarly research Zheng et al. [11-15] analyzed; the monitoring data of 10 open-cut subway stations in Xi'an and the space-time deformation during the construction of deep foundation pits in collapsible loess areas were studied. The results show that the vertical ground deformation and pile side deformation caused by digging long and deep foundation pits in collapsible loess areas increased with time. The maximum surface settlement decreased with an increase in the stiffness $(K)$ of the foundation pit support system, increased linearly with the excavation depth $(\mathrm{Hw})$, and decreased with an increase in the foundation pit height-width ratio. Chen et al. [6] used MIDAS-GTS to study the seepage field and surface settlement laws in a foundation pit project in Northeast China, concluding that surface settlement caused by precipitation is critical in the design and construction of deep foundation pits. Chen et al. [12] used a numerical calculation method to study the coupling effect of hydraulic uplift on the instability of the pit-in-pit support structure during foundation pit excavation. The results showed that the FS value increases with an increase in the impervious aquifer thickness and undrained shear strength but decreases with an increase in the pressure bearing capacity and excavation width of the foundation pit. Li et al. [16] researched foundation pit engineering under the action of tides in coastal areas, The Boussinesq function was introduced to derive the seepage equation under the influence of tides in coastal areas, and MATLAB was used to analyze the influence of the seepage field on the supporting structure of foundation pits during excavation. Xue et al. [17] analyzed the periodic changes in the seepage pressure of the foundation through field monitoring and numerical simulation using a sluice. Shen et al. [18] used the foundation pit project for Juzizhou Island Station of the Changsha Metro as an example; the proportion of grout should be adjusted to 1.4, when grouting and blocking water in areas with high water pressure. During the construction of an underground diaphragm wall in the upper soft and lower hard strata, one hydraulic grab trencher and 18 6t percussion drill trenchers should be selected to ensure smooth construction in the lower hard stratum. Zhu et al. [19] used physical model tests and Fiber Bragg Grating (FBG) displacement sensors, to study the deformation of the foundation pit under different loads and different rainfall conditions. The results show that the position of the inner pit relative to the outer pit has a significant influence on the stability of the outer pit. During the excavation of the foundation pit, the change in the soil behind the wall (pile) is a result of the combined action of the stress field and seepage field. The stress field or seepage field alone cannot accurately forecast the deformation during excavation of the foundation pit.

Achievements have also been made in the prediction of foundation pit deformation via neural network, big data processing, and numerical simulation. However, research on the supporting system and soil deformation analysis behind the wall is in the construction stage of superdeep foundation pits near water under multifield coupling and, especially, seepage and stress coupling. Therefore, this study establishes a seepage stress coupling numerical calculation model for the excavation support of a deep foundation pit adjacent to water based on a three-dimensional analysis, taking the open-cut section of the south bank of the Yellow River Tunnel Project as the engineering scenario. The horizontal displacement of the diaphragm wall, vertical settlement of the surface, uplift of the bottom soil, and variation of the seepage field at each excavation stage were analyzed. To verify the reliability of the numerical results, the measured field data were compared with the calculated values.

1.1. Biot Three-Dimensional Seepage-Stress Coupling Mathematical Model. Assuming that the soil particles in saturated soil are in compressible, seepage obeys Darcy's law. Pore water is not subject to shear stress, and water is incompressible [20]. According to the mass conservation principle 


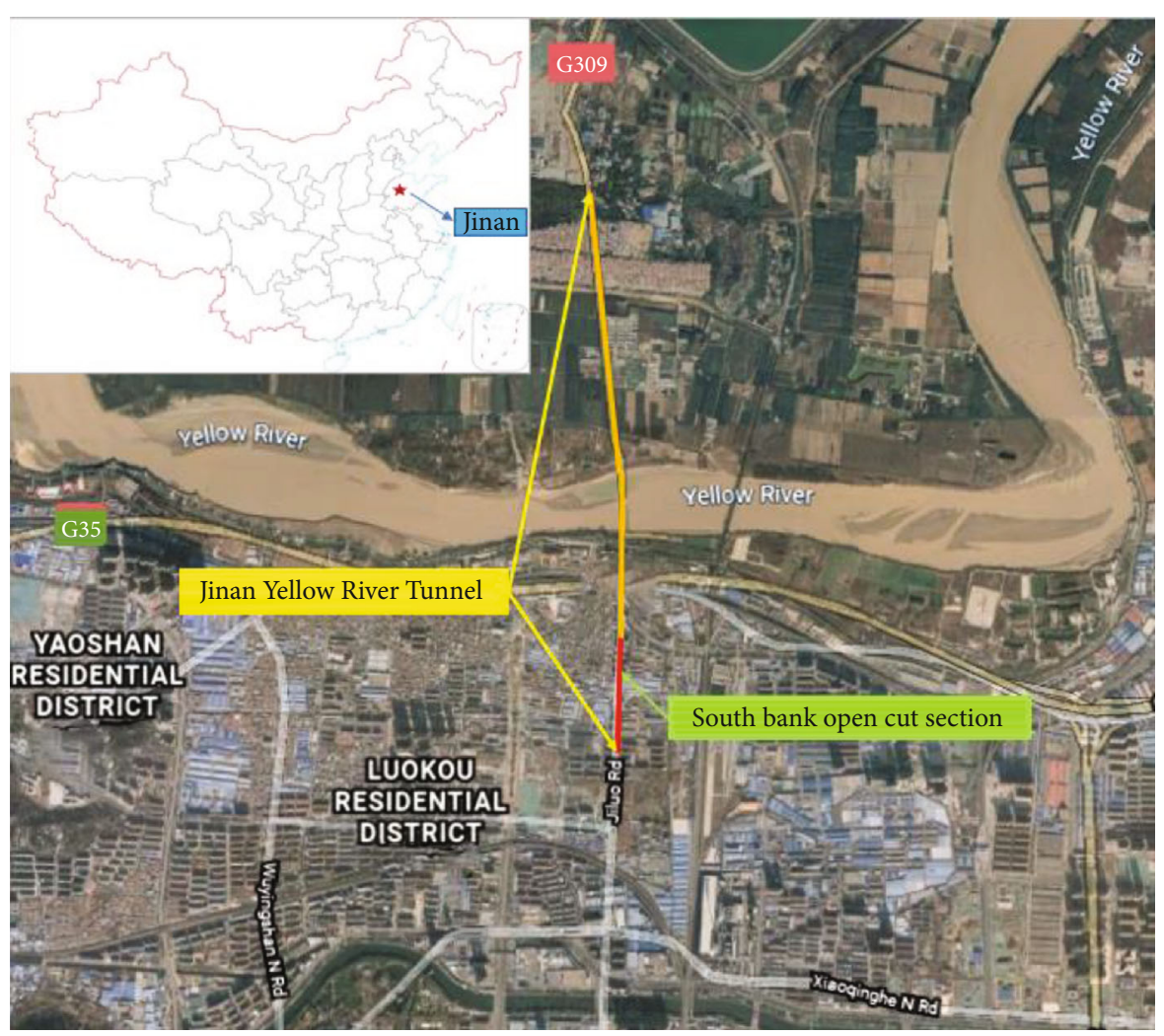

Figure 1: Map featuring the location of the field demonstration.

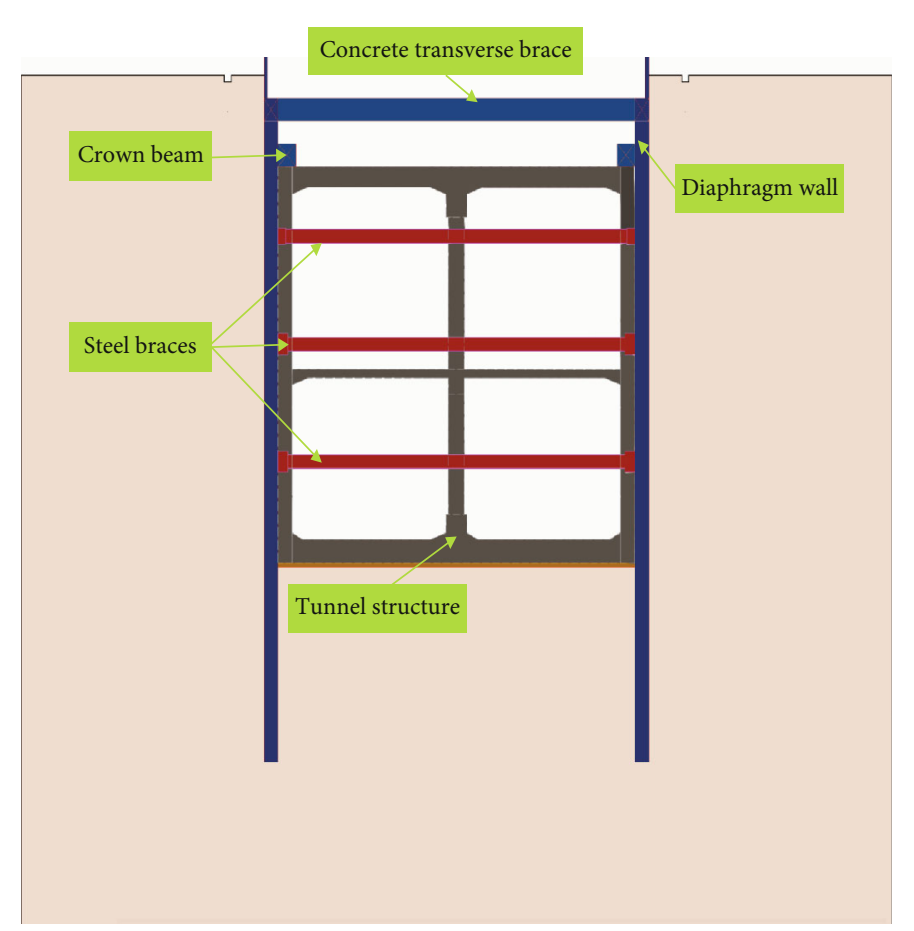

FiguRe. 2: Diagram of the Jinan Yellow River Tunnel support structures. 


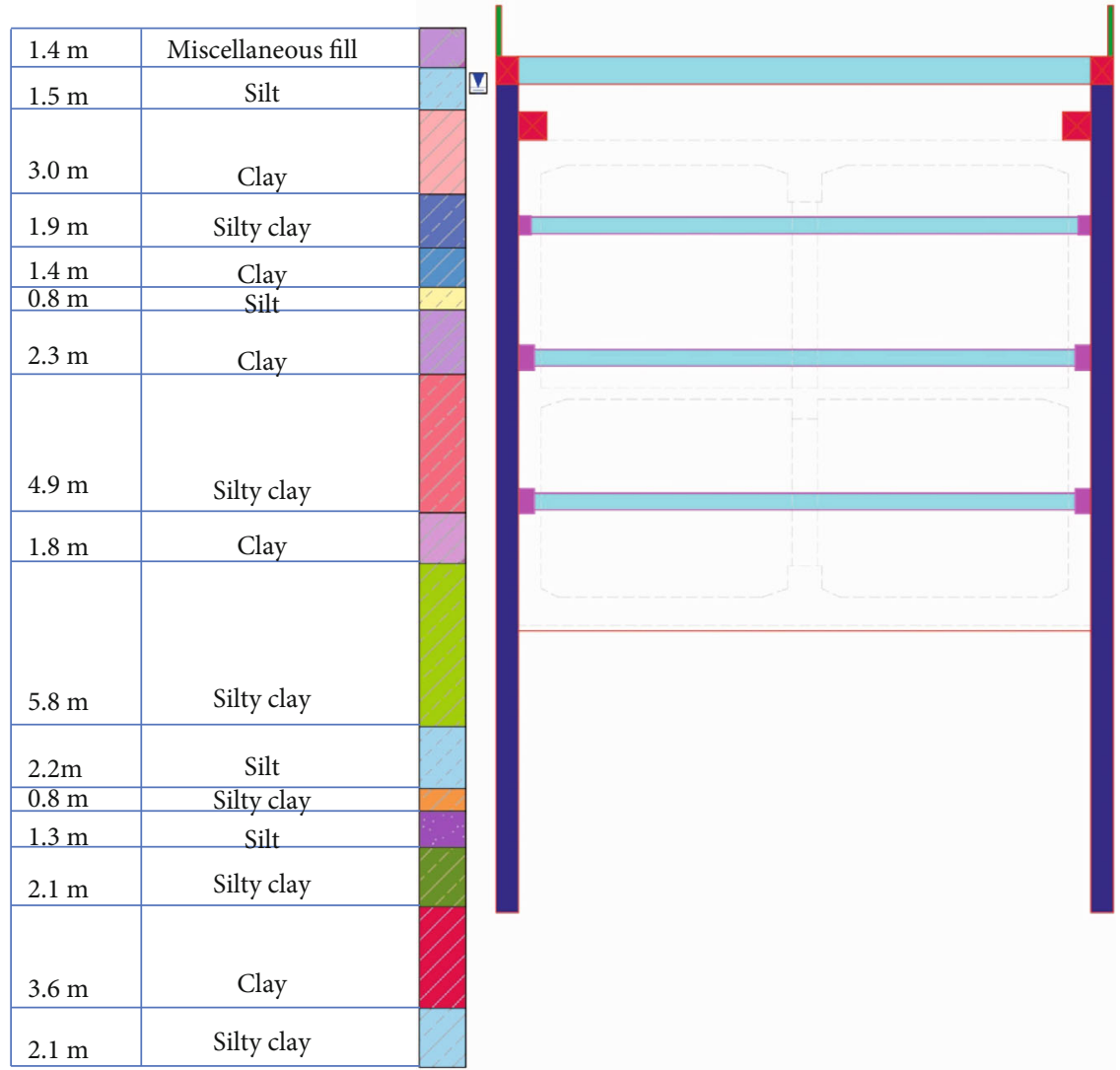

Figure 3: Soil profile compared to the depth of the tunnel supports.
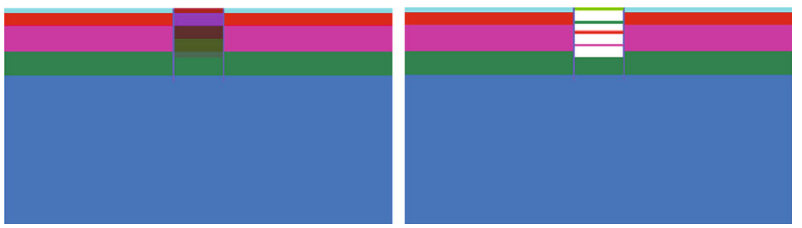

FIGURE 4: Numerical model.

and Darcy' law and assuming water flow continuity in saturated soil, three-dimensional unsteady seepage flow continuity equation can be generated under three-dimensional stress equilibrium. Using simultaneous equations, with displacement and pore water pressure, for the unknown threedimensional unsteady seepage stress coupling equation, it is possible to calculate the seepage and stress [21].

According to the law of mass conservation, the seepage continuity equation can be written as

$$
-\left(\frac{\partial \rho q_{x}}{\partial x}+\frac{\partial \rho q_{y}}{\partial y}+\frac{\partial \rho q_{z}}{\partial z}\right) \Delta x \Delta y \Delta z=\frac{\partial}{\partial t}(\rho n \Delta x \Delta y \Delta z) .
$$

The differential equation of unsteady seepage in a confined aquifer was established on the basis of the seepage continuity principle. Applying Darcy's law, the differential equation for unsteady seepage in a confined aquifer can be written as

$$
\frac{\partial}{\partial x}\left(R_{x} \frac{\partial h}{\partial x}\right)+\frac{\partial}{\partial y}\left(R_{y} \frac{\partial h}{\partial y}\right)+\frac{\partial}{\partial z}\left(R_{z} \frac{\partial h}{\partial z}\right)=S_{s} \frac{\partial h}{\partial t}
$$

If the volume force only considers gravity, the coordinate upward is positive, and the stress is positive with the pressure. According to the principle of effective stress and the threedimensional equilibrium differential and physical equations, the equilibrium differential equation of pore water pressure can be expressed as

$$
\left.\begin{array}{l}
-K \Delta^{2} L_{x}-\frac{K}{1-2 v} \cdot \frac{\partial \varepsilon}{\partial x}+\frac{\partial \mu}{\partial x}=0, \\
-K \Delta^{2} L_{y}-\frac{K}{1-2 v} \cdot \frac{\partial \varepsilon}{\partial y}+\frac{\partial \mu}{\partial y}=0, \\
-K \Delta^{2} L_{z}-\frac{K}{1-2 v} \cdot \frac{\partial \varepsilon}{\partial z}+\frac{\partial \mu}{\partial z}=-\gamma \cdot
\end{array}\right\}
$$

In the formula $\varepsilon=\left(\left(\partial L_{x} / \partial x\right)+\left(\partial L_{y} / \partial y\right)+\left(\partial L_{z} / \partial z\right)\right), G$ and $v$ represent the shear modulus and Poisson's ratio, respectively $-\Delta^{2}$ represents the Pilates operator and $\Delta^{2}=\left(\partial^{2} / \partial x^{2}\right)+\left(\partial^{2} / \partial y^{2}\right)+\left(\partial^{2} / \partial z^{2}\right)$.

In saturated soil, the variation of pore water pressure and displacement with time at any point must satisfy both the stress balance and seepage continuity equations. The basic equation of unsteady seepage-stress coupling can be derived by combining 
Table 1: Sequence of construction for the Yellow River Tunnel.

\begin{tabular}{lcc}
\hline Construction procedure & Construction content & Job content \\
\hline 1 & First-order precipitation & Water level dropped to $88.0 \mathrm{~m}$ \\
2 & First-stage excavation & Earthwork was excavated to $89.5 \mathrm{~m}$ \\
3 & First horizontal brace & Perform the first bar at $90.9 \mathrm{~m}$ \\
4 & Second & Water level dropped to $83.0 \mathrm{~m}$ \\
5 & Second & Earthwork was excavated to $84.6 \mathrm{~m}$ \\
6 & Second horizontal brace & Make the first bar at 85.4 \\
7 & Third-order precipitation & Water level dropped to $77.2 \mathrm{~m}$ \\
8 & Third-stage excavation & Earthwork was excavated to $78.7 \mathrm{~m}$ \\
9 & Third horizontal brace & Make the first bar at $80.7 \mathrm{~m}$ \\
10 & Fourth-stage precipitation & Water level dropped to $72.6 \mathrm{~m}$ \\
11 & Fourth order & Earthwork was excavated to $73.4 \mathrm{~m}$ \\
12 & Fourth horizontal brace & Make the first bar at $75.6 \mathrm{~m}$ \\
13 & Fifth-level precipitation & Water level dropped to $70.0 \mathrm{~m}$ \\
14 & Fifth-stage excavation & Earthwork was excavated to $71.0 \mathrm{~m}$ \\
\hline
\end{tabular}

TABLE 2: Soil physical parameters.

\begin{tabular}{lccccccc}
\hline Material & & \multicolumn{3}{c}{$\begin{array}{c}\text { Parameter } \\
\text { Cohesion }(\mathrm{MPa})\end{array}$} & $\begin{array}{c}\text { Friction } \\
\text { Ponosity }\end{array}$ & $\begin{array}{c}\text { Permeation } K \text { value } \\
(\mathrm{FLAC})\left(\mathrm{m}^{2} /(\mathrm{Pa} / \mathrm{s})\right)\end{array}$ \\
\hline Miscellaneous fill & 1900 & 4.3 & 2.6 & 0.038 & 16 & 0.375 & $2.51 \times 10^{-10}$ \\
Silt & 2000 & 4.7 & 2.2 & 0.041 & 25 & 0.498 & $6.31 \times 10^{-11}$ \\
Silty clay & 2000 & 6.3 & 3.6 & 0.06 & 30 & 0.479 & $1.26 \times 10^{-12}$ \\
Clay & 2100 & 4.5 & 1.8 & 0.014 & 25 & 0.463 & $3.04 \times 10^{-11}$ \\
Silty clay & 2200 & 15.3 & 3.5 & 0.015 & 30 & 0.462 & $3.32 \times 10^{-10}$ \\
\hline
\end{tabular}

the stress balance and seepage continuity equations:

$$
\left.\begin{array}{l}
-K \Delta^{2} L_{x}-\frac{K}{1-2 v} \cdot \frac{\partial \varepsilon}{\partial x}+\frac{\partial \mu}{\partial x}=0, \\
-K \Delta^{2} L_{y}-\frac{K}{1-2 v} \cdot \frac{\partial \varepsilon}{\partial y}+\frac{\partial \mu}{\partial y}=0, \\
-K \Delta^{2} L_{z}-\frac{K}{1-2 v} \cdot \frac{\partial \varepsilon}{\partial z}+\frac{\partial \mu}{\partial z}=-\gamma, \\
\frac{\partial \varepsilon}{\partial t}-\frac{\zeta}{\gamma_{w}}=0 .
\end{array}\right\}
$$

In the formula, $\varsigma=S_{x}\left(\partial^{2} \mu / \partial x^{2}\right)+S_{y}\left(\partial^{2} \mu / \partial y^{2}\right)+S_{z}\left(\partial^{2} \mu / \partial\right.$ $\left.z^{2}\right), S$ represents the permeability coefficient and $\gamma_{w}$ represents the bulk density of water.

\section{Project Summary}

2.1. Project Summary. The Jinan Yellow River Tunnel, in the middle of Jinan City, is $3.68 \mathrm{~km}$ long. It is the first large traffic tunnel across the Yellow River in China. The Jinan Yellow River Tunnel has the characteristics of a large project scale with high technical difficulty, many system interfaces, and a tight construction period. It is an important north- ward cross-section tunnel supporting the "crossriver development" strategy of Jinan City. The tunnel is a superlarge section shield tunnel, jointly constructed by the urban road and rail transit M2 line (as shown in Figure 1). The road is a 2-way, 6-lane urban trunk road with a design speed of $60 \mathrm{~km} / \mathrm{h}$.

The starting and ending points of the open-cut section of the south bank of the Jinan Yellow River Tunnel Project are $\mathrm{EK} 0+568.128 \sim \mathrm{EK} 0+974.747,406.619 \mathrm{~m}$ in length. The buried depth of the foundation floor is from 20.60 to $32.30 \mathrm{~m}$, and the overburden soil of the roof is $2.4 \sim 4.0 \mathrm{~m}$. The open-cut construction method is adopted. The open cut and hidden buried systems are 3 (four) layers with 3span box frame structure system, and the deepest buried depth of the bottom plate is $32.30 \mathrm{~m}$.

The Jinan Yellow River Tunnel adopts the underground continuous wall with internal support, construction method, and the specific support scheme is as follows: (1) a $1000 \mathrm{~mm}$ underground continuous wall is used for the retaining structure. (2) Four vertical supports are set for the foundation pit, concrete crown beams are set at the top of the wall, and roof pressing beams are set. The first support is reinforced concrete on the crown beam, and the spacing is $7.0 \mathrm{~m}$. The second support position is a steel tube support with $3.5 \mathrm{~m}$ spacing. The third consists of a reinforced concrete support 


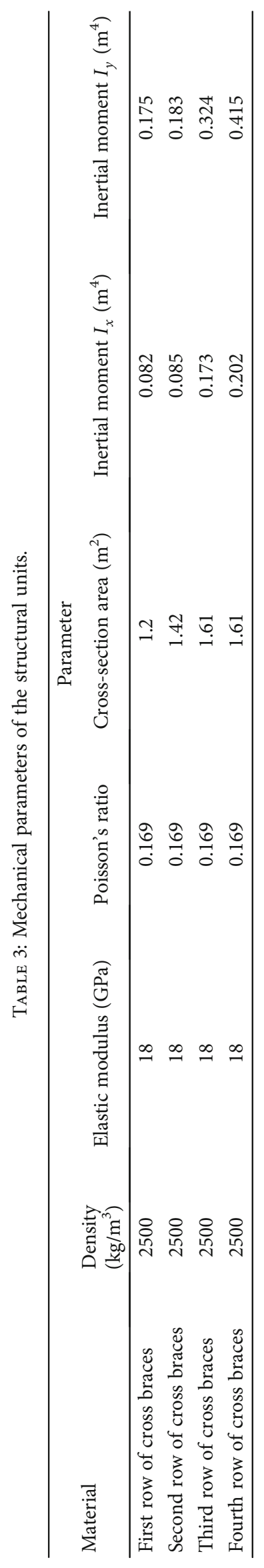




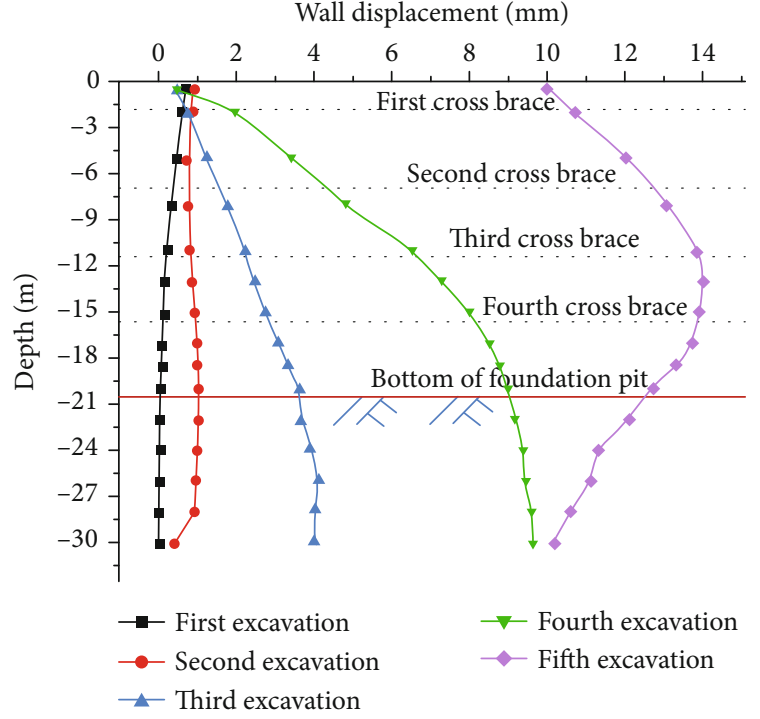

FIgURE 5: Horizontal displacement of the diaphragm wall in each excavation stage.

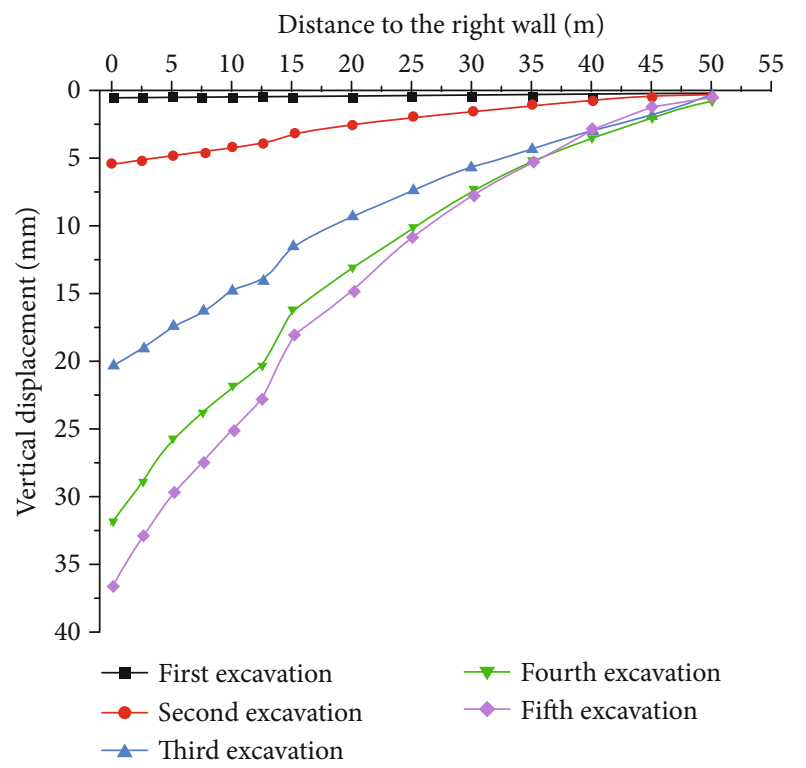

FIGURE 6: Vertical displacement of the ground surface on one side of each excavation stage.

with concrete enclosing purlin. The fourth support uses steel pipes with $3.5 \mathrm{~m}$ spacing. (3) The diaphragm wall doubles as a permanent antifloating structure (as shown in Figure 2).

2.2. Hydrogeological Condition. The geographic unit of the open-cut section on the south bank is the first-level terrace of the Yellow River. The buried depth of groundwater is $0.89 \sim 1.30 \mathrm{~m}$, the elevation is $22.77 \sim 22.96 \mathrm{~m}$, and the ground elevation is $23.76 \sim 24.60 \mathrm{~m}$. The terrain is flat, the topography is single, the main layer is relatively continuous, and there are many interlayers. The stratigraphic structure is more complicated. The stratum is mainly composed of silty clay and partly of clay. The engineering properties are gen-

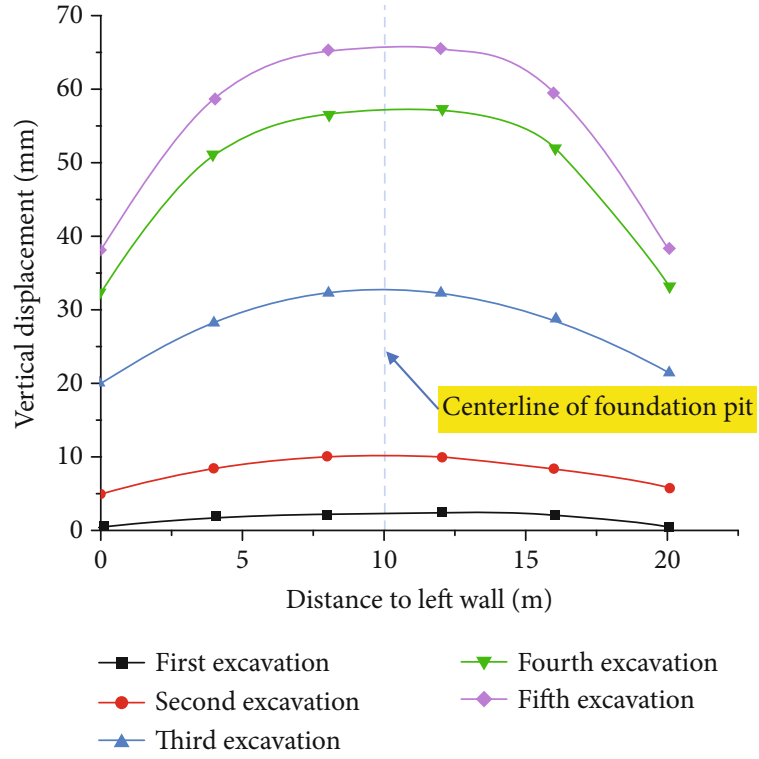

FIgURE 7: Uplift displacement of the bottom soil at each excavation stage.

eral, with weak to weak water permeability, low bearing capacity, and medium to high compressibility. It is easy to produce deformation. Silty clay is dominant below the excavation line.

The type of groundwater is pore water with Quaternary loose overburden, and its aquifers are mainly artificial fill, clayey silt, silty clay, and fine sand. Among these, the silty clay, clayey silt, and fine sand are slightly to weakly, medium to strong permeable layers, respectively (as shown in Figure 3). According to the water injection test results of the south bank working well, the comprehensive permeability coefficient of the formation is $1.48 \mathrm{~m} / \mathrm{d}$. The dynamics of the groundwater level are controlled by surface water and precipitation. The water level rises in the high water season and drops in the low water season, which is similar to the river water patterns. Groundwater flows in the direction of the river to eventual infiltration.

\section{Numeral Calculations}

3.1. Numerical Calculation Model and Boundary Conditions. An optimized numerical calculation model was established based on the geological conditions of the open-cut section on the south bank of the Yellow River Tunnel in Jinan. The size of the model was $164 \mathrm{~m} \times 91 \mathrm{~m} \times 5 \mathrm{~m}$, and the beam element was used for the horizontal support (as shown in Figure 4).

The boundary conditions of the model were as follows: the left and right boundaries constrain displacement in the $x$ direction; front and rear boundaries ( $y$ direction) constrain displacement in the $y$ direction; the bottom surface constrains displacement in the $z$ direction; pore water pressure is allowed to change; a permeable boundary is adopted; and the top surface is a free surface. 


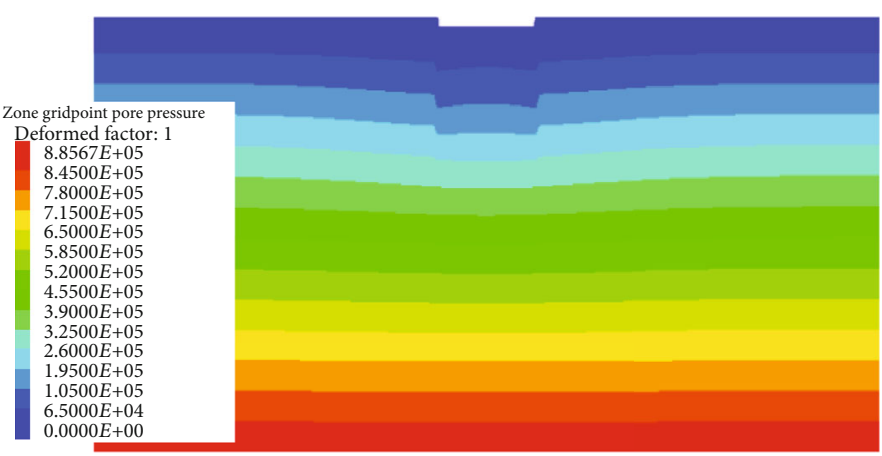

(a) First excavation

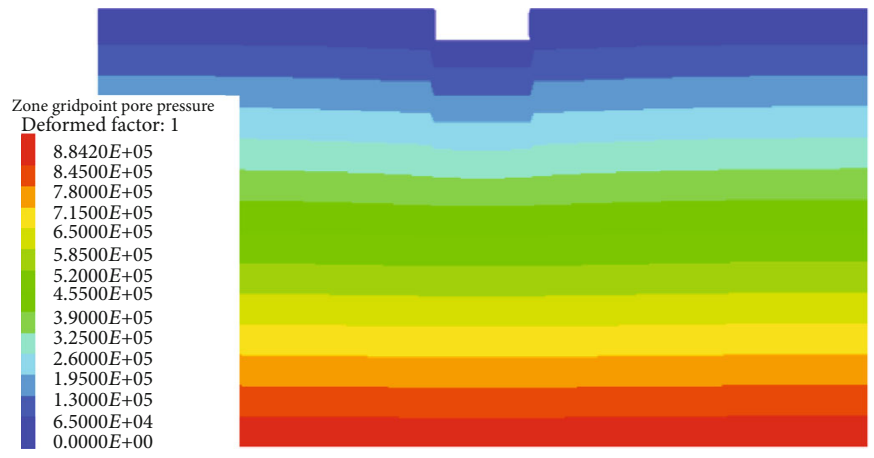

(b) Second excavation

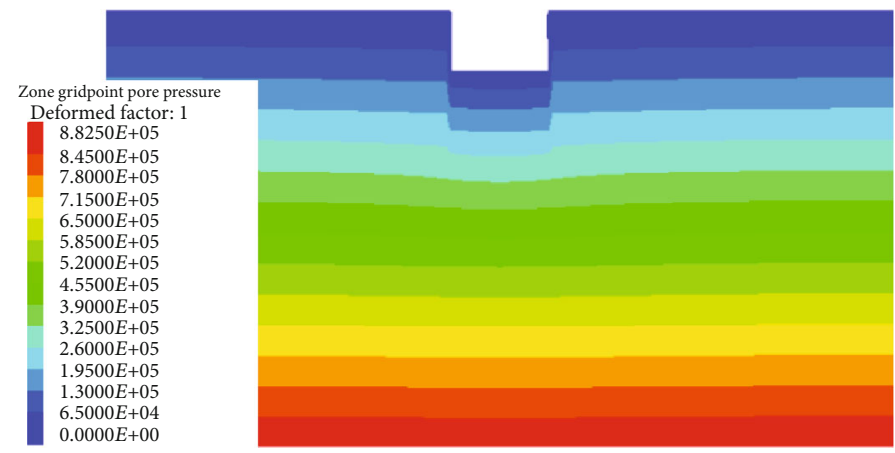

(c) Third excavation

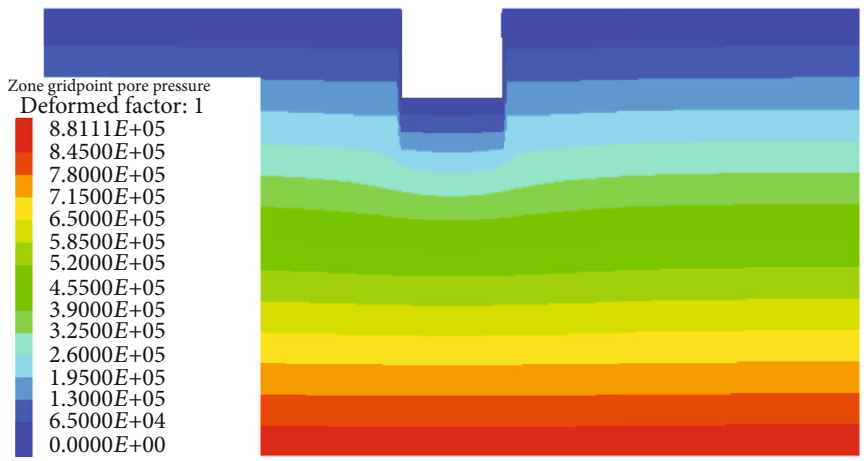

(d) Fourth excavation

Figure 8: Continued. 


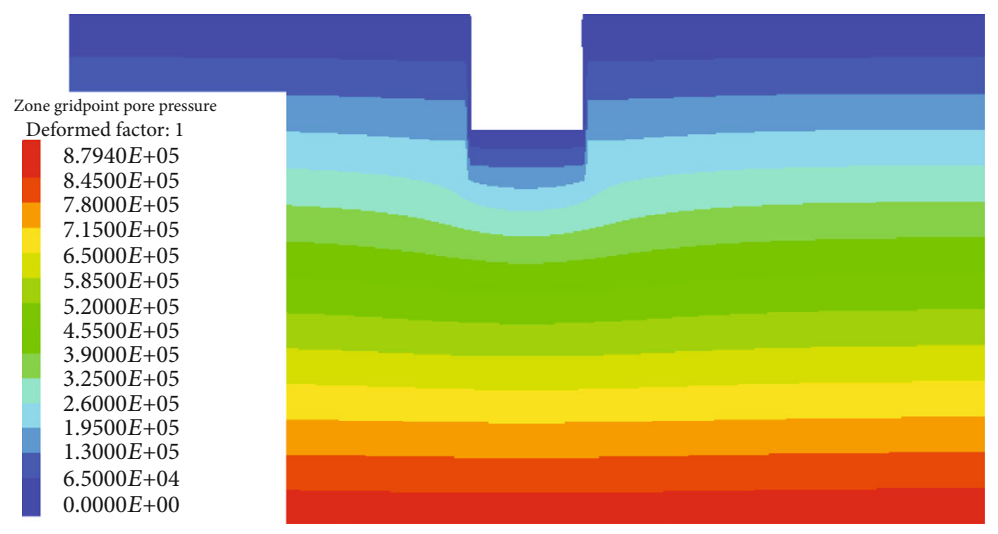

(e) Fifth excavation

Figure 8: Pore water pressure cloud diagram of each excavation step.

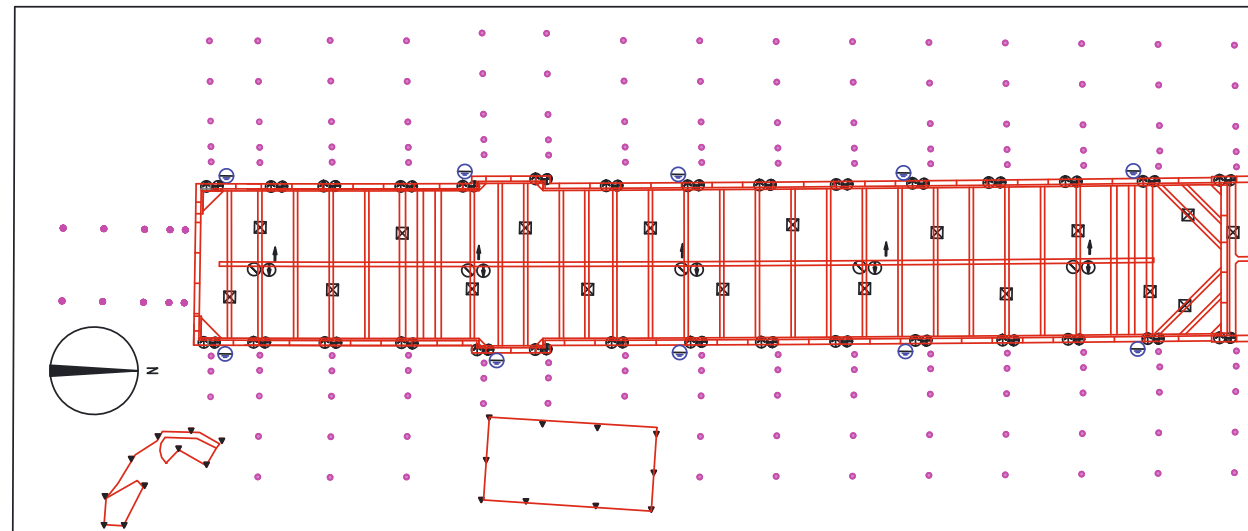

Ground settlement measuring point
Pile top horizontal and vertical displacement
measuring points
Pit bottom uplift
Groundwater level measuring point
Column horizontal displacement

$$
\begin{aligned}
& \bigotimes \text { Pile horizontal displacement measuring point } \\
& \bigotimes \text { Support axial force measuring point } \\
& \nabla \text { Building settlement, tilt measurement point } \\
& \text { D Vertical displacement of column }
\end{aligned}
$$

FIgURE 9: Plan view of typical foundation pit monitoring.

3.2. Construction Process and Parameter Selection. Foundation pit dewatering and excavation were conducted in stages to achieve "graded dewatering and graded excavation," which avoided excessive seepage pressure caused by unusually low one-time precipitation, thus causing excessive ground settlement. The construction process sequences are listed in Table 1.

To facilitate calculation, geological prospecting data for layers with similar physical and mechanical parameters were combined [22]. The simplified soil layers consisted of five layers, and the physical and mechanical parameters of rock and soil mass and structural units are shown in Tables 2 and 3, respectively. The Mohr-Coulomb constitutive model was used for the numerical calculation, the elastic constitutive model was used for the underground diaphragm wall and transverse bracing, the model config fluid mode was opened, and the isotropic seepage model was used for seepage [23].
3.3. Analysis of Calculation Results. According to the calculation model and physical and mechanical parameters, numerical calculation of the open-cut section of the south bank of the Jinan Yellow River Tunnel Project was completed, and the deformation field and pore water pressure field of the foundation pit retaining structure and surrounding soil were obtained. The horizontal displacement of the diaphragm wall, vertical displacement of the surface on one side, and pore water pressure of the uplift displacement of the soil at the bottom are analyzed in the following sections (as shown in Figures 5-8).

Figure 5 shows the underground continuous wall for each excavation stage and the horizontal displacement curve during foundation pit excavation. The constraints of the wall were improved by the stiffness of the large upper support structure. The wall itself had significant rigidity, high strength, and good integrity. The pressure of the soil under 


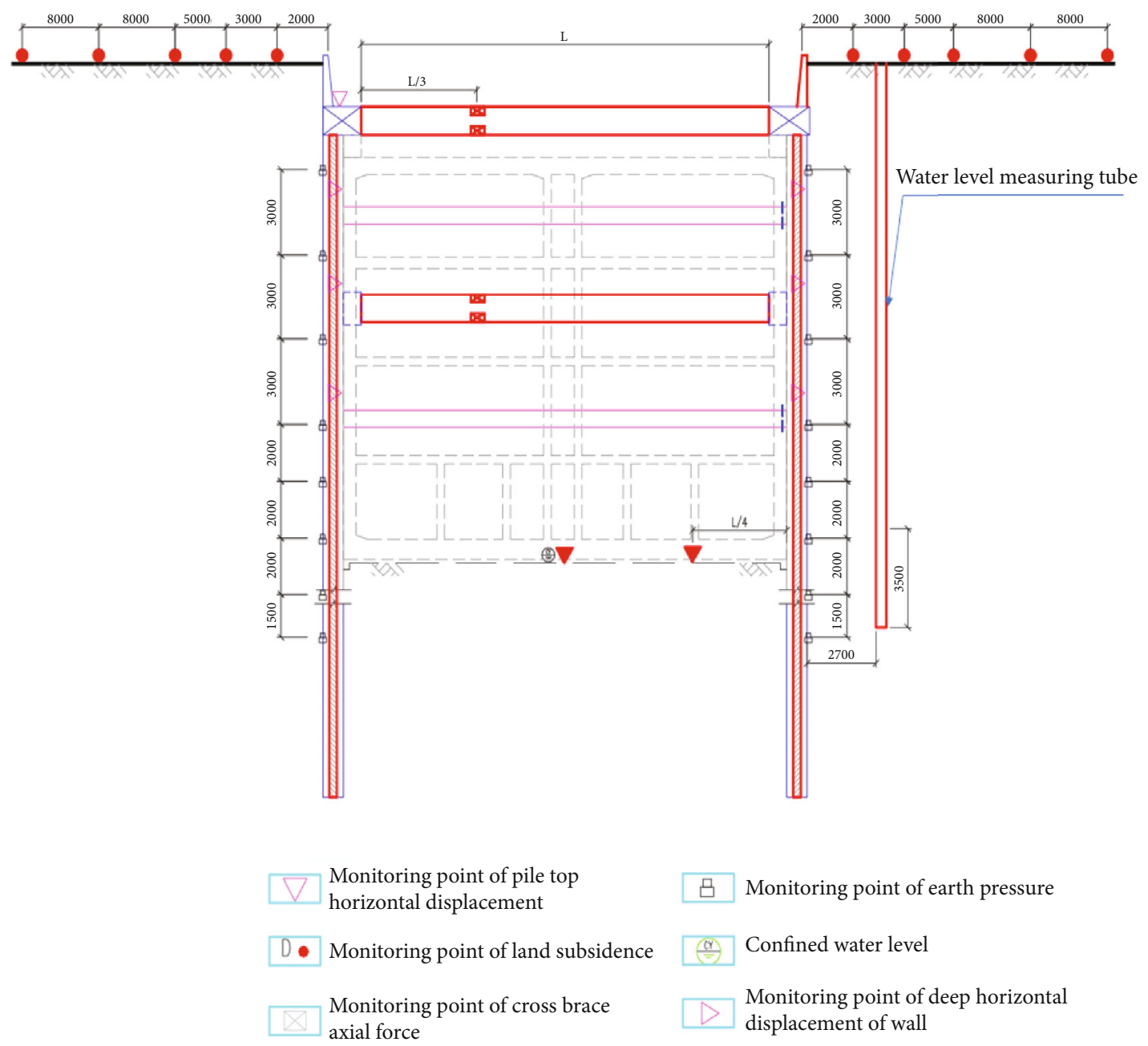

FIGURE 10: Monitoring section of a typical foundation pit.

Wall displacement $(\mathrm{mm})$

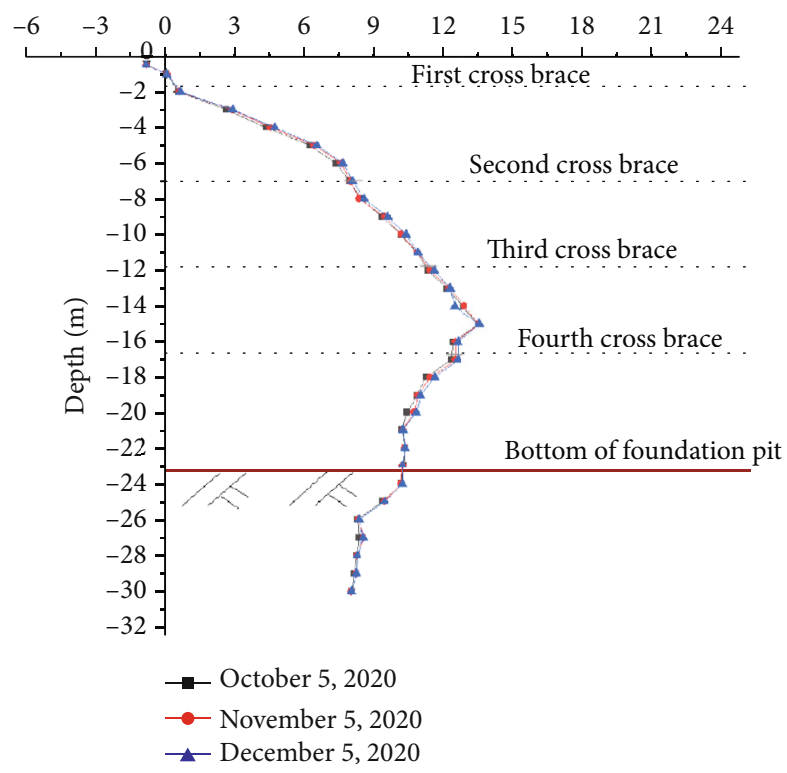

FIgURE 11: Horizontal displacement of underground diaphragm wall in typical section. the joint action of the underground continuous wall resulted in a maximum horizontal displacement of approximately $14 \mathrm{~mm}$ that occurred in the excavation face at approximately $1 / 3$ of the excavation height. According to the relationship between the horizontal displacement curve of the diaphragm wall and the displacement of the transverse bracing, the horizontal bracing effectively controlled the inward horizontal displacement of the foundation pit. The lateral displacement tended to increase with the increase in the excavation depth of the foundation pit. In the first four stages of excavation, the enclosure wall top displacement was more stable. During stage five of the excavation on top of the diaphragm wall, a displacement mutation appeared, which may be related to the bottom of foundation pit excavation. The underground continuous wall surface to increase international airport; gap increased water pressure of groundwater which created a displacement mutation, at the top of the foundation pit. The fourth and fifth stages of the underground continuous wall horizontal displacement curve were smooth, showing that a reasonable support structure significantly changed the change trend of the lateral displacement of the supporting structure, effectively protecting the foundation pit from retaining structure deformation [24]. 
According to the surface vertical displacement, the maximum surface vertical displacement occurred near the diaphragm wall at each excavation stage (as shown in Figure 6). With the increasing foundation pit excavation depth, the maximum vertical displacement of the surface presented an increasing trend. Meanwhile, the vertical displacement of the foundation pit decreased in the direction away from the excavation face with each excavation stage. A small abrupt change occurred $12 \mathrm{~m}$ away from the diaphragm wall. This was because, under the coupled action of soil and water and with the increase of the excavation depth of the foundation pit, the surface facing the diaphragm wall increased, and the soil around the foundation pit formed a stable sliding surface. The vertical surface displacement at the sliding surface appeared as the small abrupt change $[25,26]$.

According to the displacement curve representing the soil heave at the bottom of the foundation pit during each excavation stage, the displacement of soil heave at the bottom of foundation pit increased with the increasing excavation depth, the soil heave at the middle line of foundation pit was the largest, and a maximum heave of approximately $65 \mathrm{~mm}$ occurred during the fifth excavation stage (as shown in Figure 7). There was an increase in the heave uplift between the third and fourth excavation stage, mainly because for this, there was a soft soil layer between the third excavation stage (at a depth of $12 \mathrm{~m}$ ), and the fourth was silty clay. Under the coupled effect of soil and water, the lateral earth pressure at the bottom of the foundation pit increased, creating an uplift mutation. Therefore, the abundant groundwater and soft texture layer should allow effective pit dewatering and should be closed quickly to minimize the soil exposure time $[27,28]$.

The excavation pore water pressure distribution can be seen in Figure 8. The pore water pressure of the underground continuous wall was far less than the coefficient of permeability of the rock mass and generated a very good waterproof effect. During the first, second, and third excavation stage, the pore water pressure showed no apparent change nor obvious seepage $12 \mathrm{~m}$ below the excavation surface.

During steady seepage, the pore water pressure gradient at the upper part of the foundation pit did not change significantly, and the sealing effect of the diaphragm wall was significant. The contour lines of the pore water pressure of the foundation pit, especially at the foot, were dense. It can be seen from the West Law that the hydraulic gradient was large; the groundwater had a higher velocity here, and the seepage was the most significant. Therefore, especially at the foot of the foundation pit, seepage became obvious. When the embedded depth of the lower continuous wall was insufficient or row piles were used as support, water, mud, and sand inrush was likely where the rock and soil body was the weakest or mixed with sediment. Afterward, holes in the back of the piles were likely to form, affecting the stability of the foundation pit slope [29, 30]; therefore, the monitoring frequency should be increased when the construction reaches the bottom of the pit, and the secondary lining should be sealed as soon as possible.

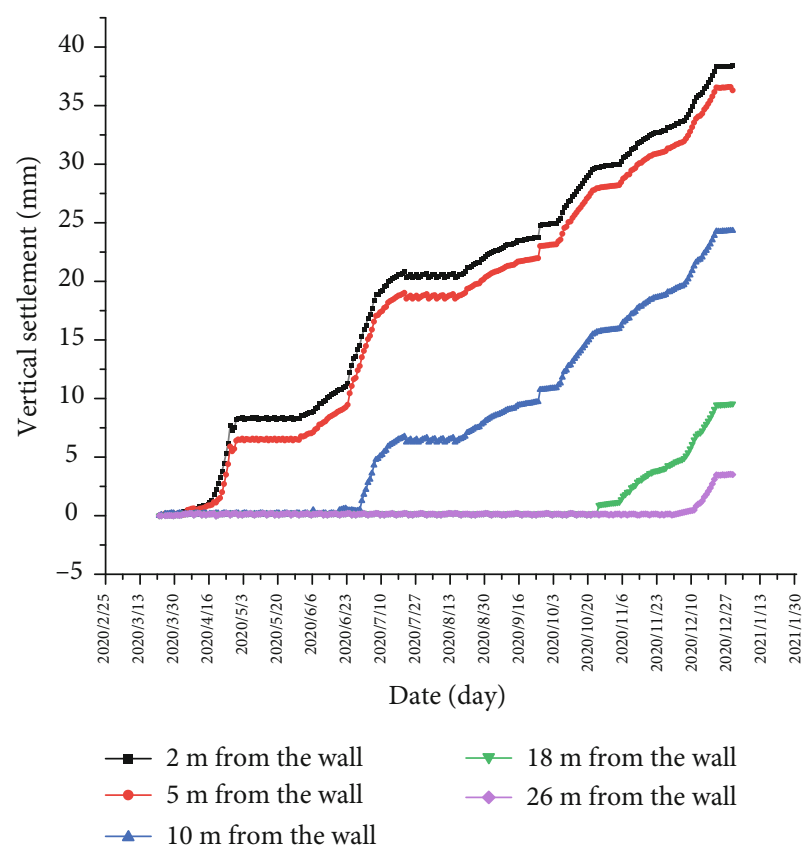

Figure 12: Vertical displacement curve of soil behind a typical section wall.

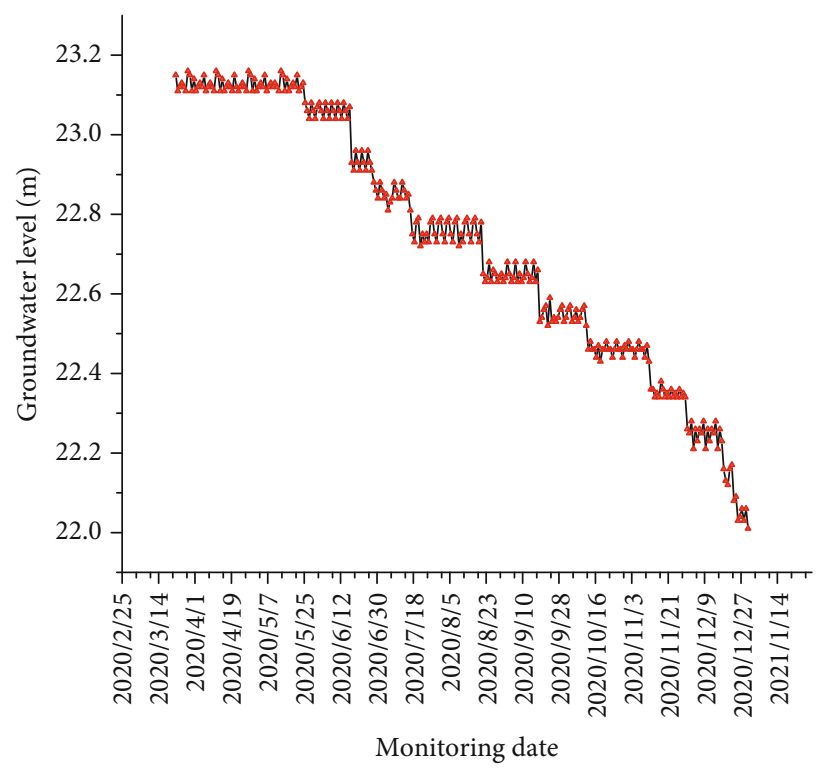

FIGURE. 13: Water level monitoring diagram.

\section{Comparison of Numerical Calculation Results and On-Site Monitoring Results}

4.1. Monitoring Plan. To determine the deformation of the foundation pit retaining structure and its influence on the surrounding rock and soil mass during the excavation of the foundation pit, the following monitoring measurements were carried out: (1) surface settlement monitoring outside the pit and the layout was arranged in the direction away from the underground diaphragm wall at intervals of $2 \mathrm{~m}$, $3 \mathrm{~m}, 5 \mathrm{~m}, 8 \mathrm{~m}$, and $8 \mathrm{~m}$; (2) horizontal displacement monitoring of the diaphragm wall was carried out along the 


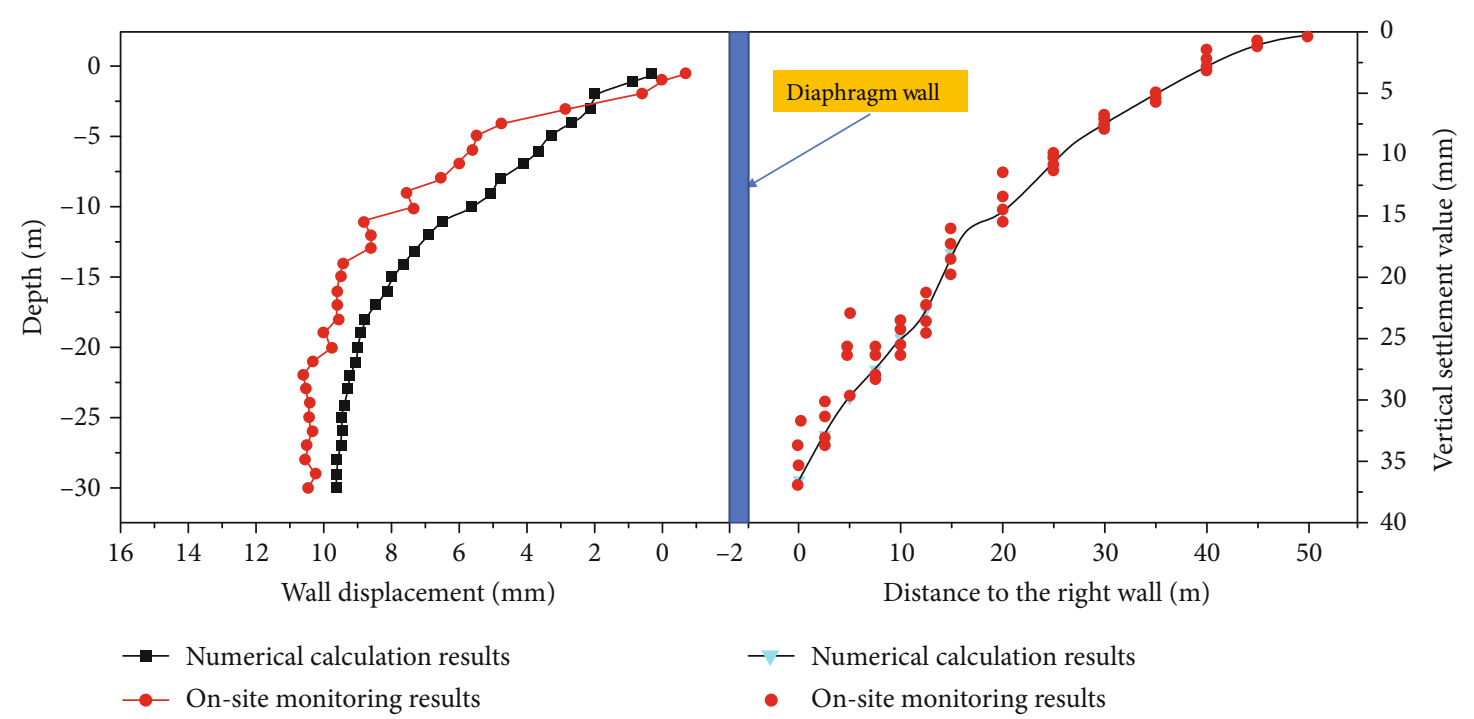

Figure 14: Comparison of displacement of underground continuous wall and wall thickness soil.

diaphragm wall at intervals of $3 \mathrm{~m} \times 3,2 \mathrm{~m} \times 3$, and $1.5 \mathrm{~m}$ from top to bottom; and (3) supporting axial force monitoring was conducted by placing monitoring points at intervals (as shown in Figures 9 and 10). To minimize errors, all monitoring equipment was carefully calibrated and installed prior to construction and the monitoring instruments were checked regularly during excavation.

4.2. Analysis of On-Site Monitoring Results. According to the underground continuous wall horizontal displacement monitoring curves during the construction of the foundation pit, the maximum horizontal displacement from the surface of the excavation to approximately 15 was $13.5 \mathrm{~mm}$. The horizontal displacement of the underground continuous wall showed a trend of steady increment to a depth of $15 \mathrm{~m}$, and the deformation of the underground continuous wall horizontal displacement curve showed a trend of overall reduction (as shown in Figure 11). When the first soil layer was excavated, the horizontal displacement of the diaphragm wall showed no obvious change, and there was a negative displacement (away from the excavation surface of the foundation pit). According to the monitoring report, one side of the foundation pit was piled with steel support and the earthwork construction machinery was working on the other side. This may explain a certain degree of negative displacement. At the positions of the second and fourth transverse braces, the horizontal displacement of the diaphragm wall again showed a small negative mutation, which indicates that the transverse braces controlled the horizontal displacement of the diaphragm wall [31].

The vertical displacement variation curves of settlement monitoring points at different distances from the diaphragm wall show that the response time of soil vertical displacement was related to the distance from the excavation surface of the foundation pit. The closer the excavation surface was, the faster the response of soil and water displacement (as shown in Figure 12). In the different excavation stages of the foundation pit, each monitoring point, especially the ones close to the excavation surface, had a higher sensitivity, the curve clearly indicating where each excavation stage began.

Figure 13 shows the ground water level curve monitoring. With the excavation of the foundation pit, the groundwater level showed a downward trend; the highest and lowest water levels were $23.12 \mathrm{~m}$ and $22.01 \mathrm{~m}$, respectively.

4.3. Comparative Analyses of Numerical Calculation Results and On-Site Monitoring Results. Comparison between the field monitoring results and the numerical calculations shows that the actual deformation of the foundation pit was consistent with the results, though the actual deformation was slightly larger (as shown in Figure 14). The numerical results show that the deformation curves of the diaphragm wall and the soil behind the wall were discrete within a small range.

Through analysis, the main reasons for the difference between the numerical simulation results and the actual situation were as follows:

(1) The current constitutive model cannot accurately reflect the deformation law of all soils in the excavation stage (Chen et al. [12], Li et al. [16], and Zhang et al. [32]). The parameters used in the calculation depended significantly on the geological prospecting data of the project, and the interval between drilling holes was $50 \sim 100 \mathrm{~m}$, which cannot accurately describe the stratification change of the excavation surface and surrounding soil. The stress field in the initial geotechnical test only considered the gravity distribution, which was different from the actual situation

(2) From the perspective of construction conditions, the excavation process of the foundation pit was complex, and the construction period was long. During the construction process, heavy construction vehicles 
and bad weather may have caused deviations between the monitoring results and the numerical calculation results

There were many factors affecting the deformation of foundation pit excavation, the material effect of precipitation; the load of surrounding buildings impacting the safety of the excavation, in addition to the calculation model effectiveness; parameter selection; construction conditions; and other factors. The calculation accuracy of the simulation software itself may have introduced errors in the results. Field monitoring may have also introduced errors as the workers' technical skill level is uneven, and the error in the monitoring instrument itself would affect the results of the monitoring $[33,34]$.

\section{Conclusions}

In this study, based on the open-cut section in the south bank of the Yellow River Tunnel Project in Jinan, the basic equation of unsteady seepage and stress coupling was derived using a Biot three-dimensional seepage and stress coupling mathematical model. By combining numerical simulation and field monitoring and considering the fluid-solid composite effect, the stability of a deep foundation pit adjacent to water was studied. The following main conclusions were obtained:

(1) The numerical results were in good agreement with the field monitoring data. The maximum horizontal displacement of the diaphragm wall occurred in the fifth excavation stage and was $14 \mathrm{~mm}$. During the entire excavation process, the horizontal displacement of the foundation pit was effectively controlled by transverse bracing

(2) Under the condition of seepage in a soft soil foundation, the maximum vertical displacement of the ground surface occurred near the diaphragm wall at each excavation stage. With an increase in the excavation depth, the maximum vertical displacement of the ground surface increased and then gradually decreased in the direction away from the excavation face

(3) When seepage was considered, the horizontal displacement of the underground continuous wall and the surface settlement decreased because of the dissipation of excess pore water pressure and seepage, which is conducive to the stability of the foundation pit. However, the soil heave at the bottom of the pit increased

(4) Restricted by assumptions and the uncertainty of parameters, the numerical simulation results and field monitoring results showed a certain degree of difference, but the results of the numerical calculation accurately reflected the surface stage of the foundation pit excavation and retaining structure, uplifts, and seepage field change law and tendencies.
Therefore, on the premise of continuing to refine the parameters and assumptions, the proposed approach represents a reasonable simplified numerical model, of actual engineering services

\section{Data Availability}

The data used to support the findings of this study are available from the corresponding author upon request.

\section{Conflicts of Interest}

The authors declare that they have no conflicts of interest.

\section{Acknowledgments}

This research was funded by the National Natural Science Foundation of China (NSFC), 360 grant number 51778351; Key Program of Shandong Provincial Natural Science Foundation of 361 China, grant number ZR2020KE013; and SDUST Research Fund, grant number 2018TDJH101.

\section{References}

[1] X. Gong and Z. Yang, "Deformation control design theory and practice in geotechnical engineering," Rock and Soil Mechanics, vol. 39, p. 273, 2018.

[2] J. Cai, C. Xie, S. Li, S. Li, and S. Zhao, "Numerical simulation of multi-layer support method for deep foundation pit under complex conditions," Engineering Mechanics, vol. 35, pp. 188-194, 2018.

[3] J. Yu, G. Xiaonan, and L. Yuanhai, "Research on deformation characteristics of deep foundation pit based on massive data," Chinese Journal of Geotechnical Engineering, vol. 36, pp. 319324, 2014.

[4] J. Sun, J. Zhou, X. Gong, and M. Zhang, "Environmental stability theory and deformation control of soils affected by construction disturbance," Journal of Tongji University (Natural Science Edition), vol. 30, pp. 1261-1269, 2004.

[5] M. Huang, X.-r. Liu, N.-y. Zhang, and Q.-w. Shen, "Calculation of foundation pit deformation caused by deep excavation considering influence of loading and unloading," Journal of Central South University, vol. 24, no. 9, pp. 2164-2171, 2017.

[6] Y. Chen, W. Zhao, J. P-j, and H. J-y, "Proportion analysis of ground settlement caused by excavation and dewatering of a deep excavation in sand area," Indian Geotechnical Journal, vol. 48, pp. 103-113, 2018.

[7] J.-l. Ma, H. Y. Aziz, C. H. Su, and C. Shi, "Settlement prediction and behaviour of pile foundations in deep clayey soil deposits," Journal of Central South University, vol. 21, no. 4, pp. 1554-1564, 2014.

[8] Z. Wang and C. Wang, "Analysis of deep foundation pit construction monitoring in a metro station in Jinan City," Geotechnical and Geological Engineering, vol. 37, pp. 813-822, 2019.

[9] X. Zhang, X. Zhang, and Y. Han, "A case study on field monitoring analysis of deep foundation pit in soft soils," Advances in Civil Engineering, vol. 2019, Article ID 9342341, 10 pages, 2019.

[10] J. Niu, Z. Li, C. Feng, B. Wang, and K. Chen, "Combined support system and calculation model for deep foundation pits in 
fill soil areas," Arabian Journal of Geosciences, vol. 13, no. 10, 2020.

[11] Y. Zheng, J. Xiong, T. Liu, X. Yue, and J. Qiu, “Performance of a deep excavation in Lanzhou strong permeable sandy gravel strata," Arabian Journal of Geosciences, vol. 13, no. 4, 2020.

[12] J. Chen, C. Lin, S. Liu, and H. Mo, "Study on supporting structure performance of deep soft soil foundation pit near sea under waves, tides, vibration, and unbalanced loads," Advances in Civil Engineering, vol. 2020, Article ID 8830199, 18 pages, 2020.

[13] F. Chen, G. Miao, and F. Lai, "Base instability triggered by hydraulic uplift of pit-in-pit braced excavations in soft clay overlying a confined aquifer," KSCE Journal of Civil Engineering, vol. 24, no. 6, pp. 1717-1730, 2020.

[14] W. Wang and X. He, "Study on the key technology of Marshland Foundation pit construction," Geotechnical and Geological Engineering, vol. 38, pp. 31-45, 2020.

[15] Y. Mei, Y.-L. Li, X.-Y. Wang, J. Wang, and C.-M. Hu, "Statistical analysis of deformation laws of deep foundation pits in collapsible loess," Arabian Journal for Science and Engineering, vol. 44, no. 10, pp. 8347-8360, 2019.

[16] S. C. Li, C. Xie, Y.-h. Liang, and Q. Yan, "Seepage flow model and deformation properties of coastal deep foundation pit under tidal influence," Mathematical Problems in Engineering, vol. 2018, Article ID 9714901, 10 pages, 2018.

[17] F. Xuefeng, Z. Wu, L. Lijun et al., "Analysis of sluice foundation seepage using monitoring data and numerical simulation," Advances in Civil Engineering, vol. 2019, Article ID 2850916, 15 pages, 2019.

[18] Y.-s. Shen, P. Wang, M. P. Li, and Q.-w. Mei, “Application of subway foundation pit engineering risk assessment: a case study of Qingdao rock area, China," KSCE Journal of Civil Engineering, vol. 23, no. 11, pp. 4621-4630, 2019.

[19] C. Zhu, K. Zhang, H. Cai et al., "Combined application of optical fibers and CRLD bolts to monitor deformation of a pit-inpit foundation," Advances in Civil Engineering, vol. 2019, Article ID 2572034, 16 pages, 2019.

[20] P. Dobak and J. Gaszynski, "Evaluation of soil permeability from consolidation analysis based on Terzaghi's and Biot's theories," Geological Quarterly, vol. 59, pp. 373-381, 2015.

[21] Z. J. Luo and F. Zeng, "Finite element numerical simulation of land subsidence and groundwater exploitation based on viscoelasticplastic Biot's consolidation theory," Journal of Hydrodynamics, vol. 23, no. 5, pp. 615-624, 2011.

[22] S. A. Ahmed, Y. Cho, T. Fasih, M. N. Anjum, and X. H. Dong, "Finite-difference numerical simulation of dewatering system in a large deep foundation pit at Taunsa Barrage, Pakistan," Sustainability, vol. 11, 2019.

[23] P. F. Luo and C. H. Li, "Numerical simulation analysis of the influence of foundation pit excavation on the surrounding buildings of an office building," IOP Conference Series: Earth and Environmental Science, vol. 252, 2019.

[24] N. Q. Zhou, P. A. Vermeer, R. X. Lou, Y. Q. Tang, and S. M. Jiang, "Numerical simulation of deep foundation pit dewatering and optimization of controlling land subsidence," Engineering Geology, vol. 114, no. 3-4, pp. 251-260, 2010.

[25] J. F. Wang, H. W. Xiang, and J. G. Yan, "Numerical simulation of steel sheet pile support structures in foundation pit excavation," International Journal of Geomechanics, vol. 19, no. 4, article 05019002, 2019.
[26] K. W. Ding and M. G. Wang, "The numerical simulation of the surface settlement and the pile horizontal displacement caused by the foundation pit dewatering," Materials in Environmental Engineering, pp. 1303-1312, 2017.

[27] S. W. Hou, S. P. Guo, S. H. Ma, and X. L. Liu, "Stability parameter analysis and deformation simulation of subway foundation pit," in Proceedings of the 2017 3rd International Forum on Energy, Environment Science and Materials (Ifeesm 2017), vol. 120, pp. 318-323, Shenzhen, China, 2017.

[28] Y. F. Li, J. R. Chai, and Z. G. Xu, "Analysis of influence of seepage on stability of foundation pit," in 4th International Conference on Advanced Composite Materials and Manufacturing Engineering 2017, vol. 207, Xishuangbanna, Yunnan, China, 2017.

[29] Y. Ni and Y. L. Zheng, "Reliability analysis of slope stability of foundation pit excavation with changes of intermediate principal stress," Agro Food Industry Hi-Tech, vol. 28, pp. 27792784, 2017.

[30] Y. H. Li, M. Q. Nie, and Y. L. Fan, "Stability analysis of foundation pit under bottom over-excavation and top overloading conditions," in International Conference on Power Engineering \& Energy, Environment (Peee 2016), pp. 674-679, Shanghai, China, 2016.

[31] Y. Miao, B. Liu, C. Liu, Z. Shu, and H. Wu, "Experimental study on stability analysis of a structure during excavation beneath this structure," Advances in Civil Engineering, vol. 2020, Article ID 9268927, 14 pages, 2020.

[32] X. Zhang, G. Wei, and C. Jiang, "The study for longitudinal deformation of adjacent shield tunnel due to foundation pit excavation with consideration of the retaining structure deformation," Symmetry, vol. 12, no. 12, p. 2103, 2020.

[33] Z. Shi, Q. Wang, and L. Xu, "Experimental study of cement alkali-resistant glass fiber (C-ARGF) grouting material," Materials, vol. 13, no. 3, p. 605, 2020.

[34] L. Jie, Y. Yueguan, L. Jun, L. Xuesong, and H. Zhihua, "Based on laser point cloud to calculate the horizontal displacement of subsidence area," Coal mining, vol. 21, pp. 99-102, 2016. 